\title{
El diálogo intergeneracional de la familia Crecente en $O s$ libros arden mal de Manuel Rivas
}

\author{
The Intergenerational Dialogue of the Family Crecente in \\ Os libros arden mal by Manuel Rivas
}

\author{
Anna LAMmers \\ Universidad Christiana Albertina de Kiel \\ Seminario de Lenguas y Literaturas Románicas \\ alammers@romanistik.uni-kiel.de \\ [recibido 30/10/2014, aceptado 26/01/2015]
}

\begin{abstract}
Somos lo que recordamos. El olvido que seremos. Por un lado, la potencia genésica de la memoria, de Mnemósine, la madre de las nueve musas. Por otro, la constatación de que la historia de la humanidad es una dramática historia del olvido (Rivas 2008: 215)
\end{abstract}

\section{RESUMEN}

Este artículo tiene la intención de estudiar el diálogo intergeneracional de la familia Crecente en la novela Os libros arden mal (2006) del escritor gallego Manuel Rivas. A partir de los conceptos teóricos de la memoria colectiva, la memoria cultural y del trauma colectivo, desarrollados en las Ciencias Sociales y Culturales por Halbwachs (1925), Assmann (1992) y Kühner (2008), se procede al análisis del campo traumático de la memoria familiar y la transmisión de recuerdos de la Guerra Civil y el Franquismo.

PALABRAS ClAVE: Literatura gallega, Manuel Rivas, Guerra Civil española, memoria histórica, transmisión intergeneracional.

\section{RESUMO}

Este artigo ten a intención de estudar o diálogo interxeracional da familia Crecente na novela Os libros arden mal (2006) do escritor galego Manuel Rivas. A partir dos conceptos teóricos da memoria colectiva, memoria cultural e do trauma colectivo, desenvolvidos nas Ciencias Sociais e Culturais por Halbwachs (1925), Assmann (1992) e Kühner (2008), procédese á análise do campo traumático da memoria familiar e a transmisión das lembranzas da Guerra Civil e do Franquismo.

PALABRAS CHAVE: Literatura galega, Manuel Rivas, Guerra Civil española, memoria histórica, transmisión interxeracional.

\section{ABSTRACT}

This article analyses the dialogue of the Crecente family in the novel Oslibrosarden mal (2006) of the Galician writer Manuel Rivas. From the theoretical concepts in collective memory, cultural memory and collective trauma, developed in Social and Cultural Sciences by Halbwachs (1925), Assmann (1992) and Kühner (2008), the analysis focuses on the family's traumatic memories of the Civil War and Franco's regime and how they were transmitted.

KEY WORDS: Galician literature, Manuel Rivas, Spanish Civil War, historical memory, intergenerational transmission.

Lammers, A. (2015): "El diálogo intergeneracional de la familia Crecente en Os libros arden mal de Manuel Rivas", Madrygal (Madr.), 18, Núm. Especial: 107-113.

SUMARIO: 1 . Introducción. 2. Aspectos de un pasado colectivo: la familia Crecente y el diálogo intergeneracional. 2.1. Oralidad y memoria: la relación dialógica entre padre e hija. 2.2. Memorias traumáticas en Os libros arden mal: los casos de Olinda y Pinche. 2.3. Conclusión parcial: silencio y diálogo entre dos generaciones. 3. Memorias, olvidos y silencio: transmisión intergeneracional del trauma. 4. Conclusiones. 5. Referencias bibliográficas. 


\section{INTRODUCCIÓN}

En la narrativa española contemporánea relacionada con la Guerra Civil y el Franquismo se manifiesta como una pregunta sumamente relevante "la transmisión del testimonio y la cuestión de en qué medida la memoria puede ser legada, de manera verídica de una generación a la otra -sea a través de transmisión escrita u oral (...)", tal y como lo mencionó Mechthild Albert (2006: 21). Manuel Rivas es un escritor que se acerca literariamente a la época de la Guerra Civil española y al Franquismo. Sus novelas se apoyan, mayoritariamente, en hechos reales, pero se desarrollan en el mundo de la ficción. En su novela Os libros arden mal (2006) ${ }^{1}$, analizada a continuación, la ficción literaria tiene una función anamnésica. A través de los diálogos de los protagonistas, Manuel Rivas invita al lector a reconstruir la vida de individuos y familias que han vivido la Guerra Civil y sus consecuencias, con el fin de aumentar el conocimiento de los seres que no la han experimentado. Tal y como lo explica el propio autor en su libro A cuerpo abierto (2008), las consecuencias de la Guerra Civil y la dictadura son problemas contemporáneos, que hasta hoy no se han solucionado suficientemente en el ámbito socio-político:

Hasta ahora, la exploración del mapa del dolor, los trabajos de exhumación de desaparecidos, las movilizaciones para retirar la simbología ominosa de los amigos de Hitler y Mussolini, las iniciativas para alumbrar zonas ocultas del thriller franquista (...) no han sido obra de la Justicia, sino el fruto de un trabajo ímprobo (...) (Rivas 2008: 214)

Todas estas razones llevan al autor a construir un espacio discursivo en el mundo ficcional. A este respecto conviene recordar además el hecho de que durante el Franquismo existía sólo una memoria oficial. En consecuencia quedaron en el subconsciente muchas memorias individuales y familiares, que de una manera $u$ otra se transmitieron de generación en generación por vía oral.
La novela Os libros arden mal se apropia de una dimensión colectiva de la memoria para reconstruir en el medio de la ficción la realidad española desde la Guerra Civil hasta los años 90. Este libro llama la atención sobre las circunstancias alrededor del golpe militar y la quema de libros en A Coruña el 19 de agosto de 1936 y pone el acento en los siguientes temas: primero, el estado psicosocial de las personas que han vivido la guerra y la dictadura; segundo, el papel de la memoria individual frente a la memoria colectiva y tercero, la transmisión de la experiencia de la guerra de una generación a otra. Este artículo se centrará en la transmisión oral con el fin de mencionar algunos ejemplos de la novela en que esta transmisión, sea de forma directa o indirecta, amplia el conocimiento de los personajes que no han vivido la guerra personalmente.

Para esta tarea sirven de base los conceptos teóricos desarrollados en las Ciencias Sociales y Culturales, es decir, el concepto de la mémoire collective de Maurice Halbwachs (1925), la distinción entre memoria colectiva y memoria cultural de Jan Assmann (1992) y la teoría del trauma colectivo de Angela Kühner (2008). Pese a no entrar en ellos de forma muy detallada, se describirán sin embargo algunas cuestiones detalladas sobre los mismos. Siguiendo a Halbwachs, se observa que los recuerdos de cada individuo se estructuran de una forma u otra dentro de un grupo. En el contexto familiar esto significa que la construcción de la memoria no se lleva a cabo sólo a partir de los recuerdos autobiográficos, sino también de los recuerdos familiares y además, el intercambio de recuerdos, de una manera o de otra, forma la identidad del individuo. En este sentido, se podría destacar que el pasado es una reconstrucción originada y formada por el entorno social -del público, de la sociedad y de la familia ${ }^{2}$.

\footnotetext{
${ }^{1}$ Para este trabajo se utilizará la traducción al español de Dolores Vilavedra (Rivas 2007).

${ }^{2}$ Me refiero sobre todo a los capítulos III y V de Les cadres sociaux de la mémoire (1952); la primera edición fue publicada en 1925 (Paris, Librairie Félix Alcan).
} 
Según Assmann, en relación a la memoria colectiva hay que diferenciar entre memoria comunicativa y memoria cultural (2007: 50) ${ }^{3}$. La memoria comunicativa se basa en los recuerdos personales de los testigos que se transmiten de una generación a otra de forma oral, mientras que la memoria cultural se refiere a acontecimientos más lejanos cuyos testigos ya no están vivos. Las experiencias del pasado, significativo para la identidad colectiva, se transmiten de generación a generación simbólicamente en forma de conmemoraciones, objetos, imágenes, $\mathrm{y}$, sobre todo, narraciones.

Además, se necesita resaltar que, tras una guerra, la conciencia colectiva puede mostrar malformaciones psíquicas. Siguiendo a Ana Luengo, tras situaciones límites "se crean ciertas psicosis que responden a una gran presión de angustia, terror e incertidumbre, así como a la desorganización y al desmoronamiento de los referentes que antes habían dado coherencia y sentido de permanencia a los individuos" (2004: 83). Para analizar de qué forma se manifiestan esos diferentes elementos traumáticos que señala Luengo, se empleará también la distinción de Kühner ente trauma primario y trauma secundario ${ }^{4}$. Todos estos conceptos serán aplicados a la novela de Rivas escogida, centrándose en el diálogo intergeneracional de una familia retratada en esta ficción: la familia Crecente.

\section{ASPECTOS DE UN PASADO COLEC- TIVO: LA FAMILIA CRECENTE Y EL DIÁLOGO INTERGENERACIONAL}

La familia Crecente pertenece al grupo de los vencidos de la guerra que se rebela tanto contra el régimen fascista como contra la memoria oficial, impuesta por los vencedores. Alrededor del hilo argumental básico, la quema de libros, se estructura la vida de la familia Crecente: Francisco, llamado Polca, jardinero y enterrador -también enterrador de libros-, su mujer Olinda y sus hijos Ó y Pinche. A partir de ahí, se analizarán las relaciones familiares -especialmente las existentes entre padre-hija y entre madre-hija-y se estudiarán las siguientes cuestiones: ¿Cómo se configura una memoria del pasado traumático? ¿Qué es predominante: el diálogo o el olvido? ¿Es conveniente hablar de una transmisión de la experiencia traumática de una generación a otra?

\subsection{ORALIDAD Y MEMORIA: LA RE- LACIÓN DIALÓGICA ENTRE PADRE E HIJA}

La primera relación que conviene mencionar es la existente entre Polca y Ó Crecente. Dentro del ámbito familiar de los Crecente, el padre, Polca, juega un papel importante porque es el personaje que genera la discusión sobre el pasado. Ó, la hija, aparece como interlocutora y oyente del padre y entre estos dos personajes persiste una memoria íntima. De manera didáctica y cariñosa Polca despierta la conciencia de la hija acerca de un período que, aunque no le es del todo ajeno, ella no ha vivido personalmente. Entre estas dos memorias individuales se cruzan espacios del presente y del pasado con el fin de formar una versión común, una memoria familiar, que tiene una función estabilizadora en cuanto a la identidad colectiva de la familia.

Para Polca, el lenguaje tiene un valor transcendental ya que a través de este se garantiza la transmisión de la historia -pasada y reciente. Además la palabra es la portadora del saber, el arma para enfrentarse al mundo -esto explica su empeño en la transmisión de sus conocimientos a sus descendientes.

A través del diálogo entre padre e hija, Polca, por un lado, relata a Ó sus experiencias y su versión de la historia y, por otro, le lega un arma de valor incalculable, el arranque, la capacidad para enfrentarse a la vida: "Yo por suerte he tenido a Polca. A pai pai. Creo que, si

\footnotetext{
${ }^{3}$ En este trabajo se utiliza la sexta edición de 2007.

${ }^{4}$ Según Kühner se distingue entre un trauma primario para la generación directamente afectada y un trauma secundario, "Zuschauertrauma" (2008: 58) para la generación sucesiva.
} 
no fuese por él, no habría arrancado. Sería feliz. Sería infeliz. Sería muda. Aún me mearía en la cama" (Rivas 2007: 279).

Según Assmann, la memoria individual sobrevive al conectar el pasado con el presente por medio de la tradición oral (2007: 50). Polca siente irremediable y profundamente la necesidad de narrar, de transmitir experiencias e historias locales tanto para guardar y ceder su experiencia personal como para recuperar las huellas de la memoria de grupos "olvidados". Este personaje se empeña en reivindicar las "otras" memorias de la historia, las silenciadas y reprimidas, por ejemplo las de sus compañeros, estos "muchachos alegres" (Rivas 2007: 35), que "hablaban de la revolución como de una fiesta" (Rivas 2007: 35), pero cuyas vidas finalmente cambian de forma brutal.

(...) el tren especial nunca llegó a salir. Ni las lanchas. Y ellos no subieron aquel 2 de agosto río arriba hacia el campo de la fiesta, Libertaria por un día, sino que muchos bajarían como cadáveres aquel mismo mes, arrojados a las aguas un tramo más arriba, desde el puente de la Castellana, en la carretera de Coruña a Madrid. (Rivas 2007: 533-534)

Resulta significativo, que Polca sitúa a Ó como testigo de los acontecimientos del pasado, haciéndole portadora de ese pasado y contribuyendo a garantizar el futuro de la memoria reprimida en nuevas generaciones.

¿Y qué pasó? (...) Lo mataron como a un Cristo. Aquí no hubo guerra, nena, eso que llaman guerra fue una cacería (...) ¿Y qué pasó con el letrero del sol? Lo hicieron añicos. ¿Y el ateneo, y los libros? Los quemaron. ¿Quemaron los libros? Sí. (...) El futuro es incierto, dijo Polca. No sabemos lo que va a pasar. Quizá llegará un momento, hija, en que sólo tú sabrás quién era Arturo da Silva, y que existió El Resplandor en un lugar ahora tan tristón. (Rivas 2007: 400-401)

\subsection{MEMORIAS TRAUMÁTICAS EN $O S$} LIBROS ARDEN MAL: LOS CASOS DE OLINDA Y PINCHE

Para analizar la representación de los efectos traumáticos de la Guerra Civil y la consiguiente dictadura en la novela de Rivas se examinará, en particular, la relación entre madre e hija, entre Ó y Olinda. La madre, que ha presenciado personalmente la guerra, vive cada vez más retirada del mundo y huye de la realidad. Así, con el paso de tiempo, Olinda irá enmudeciendo progresivamente y su hija Ó le servirá de portavoz:

Se ve que ella escoge las palabras. Para decirlas y también para oírlas. Incluso cuando habla Polca. No le molesta que él sea como una radio. Pero no lo escucha todo el tiempo. Yo me fijo en que a veces él está radiando y ella está sumida en el silencio. Pero, de repente, sale de ese agujero y atiende, o lanza una risa. Ésas son las palabras que valen. Quién pudiese saber cuáles son. (Rivas 2007: 212-213)

Como pondrán de relieve las siguientes citas, la hija distingue entre el padre y la madre en cuanto a la voluntad y a la capacidad de narrar el pasado, diciendo sobre el padre: "Ese hablar a solas. Polca, Polca. Tú eres un padre de verdad" (Rivas 2007: 401) y, sobre la madre: "Olinda casi no habla de su vida. Le gustan las radionovelas, se queda absorta, fuera del tiempo" (Rivas 2007: 401).

Se destaca además como Ó observa también las marcas visibles del trauma $\mathrm{y}$, por ejemplo, comprueba como su madre "es dura hacia dentro" (Rivas 2007: 15), "Está a contraluz, lleva el pelo recogido en un pañuelo atado en la nuca y ahora vuelve a mostrar el rictus de la dureza. Es dura hacia dentro" (Rivas 2007: 15).

En este sentido, se puede concluir que Ó ocupa una función diferente para el padre y la madre: siendo la oyente y transmisora de recuerdos para el padre, la portavoz para la madre. La hija es capaz de leer las huellas traumáticas que el pasado ha dejado, psíquica y físicamente, en sus progenitores y, por ello, está dispuesta a proteger y transmitir todos estos recuerdos familiares. Dentro del colectivo Crecente, la hija tiene un papel transcendental como depositaria de las memorias de familiares y personas allegadas. Se convierte en la instancia que habla del pasado cuando la memoria de la primera generación desaparece.

A este respecto hay que hacer hincapié en el hecho de que, aparte de la transmisión directa 
del padre, la madre, Olinda, también transmite su memoria, pero de forma diferente: A Olinda, "se le metió el silencio dentro del cuerpo" (Rivas 2007: 212). Por ello, mientras que ella, literalmente, habla cada vez menos, su cuerpo habla cada vez más. Sus cicatrices traumáticas se hacen visibles, en su mirada, en sus gestos, en su manera de hablar escasa, lenta y baja. En consecuencia, los recuerdos e incluso la voz de Olinda están transformándose en los de Ó. Se podría afirmar que no solo a partir del diálogo se traspasan los recuerdos de la guerra, sino también a partir de los silencios. Por ello la relación entre Olinda y Ó podría definirse como una relación no verbal, es decir un "diálogo somático".

El análisis de la figura de Olinda hace evidente que existen vivencias pasadas que no pueden ser integradas narrativamente. La madre es incapaz de rebelarse con vehemencia contra un sistema político-social injusto y pierde constantemente su memoria y la capacidad de conectarse con la realidad. En consecuencia, su carácter -su identidad personal- está cambiando:

Porque Olinda no es que fuese tartamuda, ni se le trabase la lengua. Olinda era muy avispada. Y dicen que de joven, cuando trabajó de cerillera en la fábrica de Zaragüeta, armaba ella sola una juerga, la alegría del pabellón de cajas, "la chispa de Castiñeiras", en palabras de Polca, lo que ya era mucho decir en la fábrica de fósforos. (...) Algo pasó con Olinda, que se le metió el silencio dentro del cuerpo. (Rivas 2007: 212)

Otro miembro familiar sumamente traumatizado es Pinche. El hijo pequeño también está marcado por la experiencia traumática que sigue estando viva, aunque sea sólo en su subconsciente, donde ha dejado un sello en su personalidad. Él somatiza el silencio de la madre y sufre por causa de un traumatismo prenatal, que va a agravarse durante la fase infantil.

Guillerme, Pinche, mi hermano pequeño, se parece mucho a ella, a Olinda. Nació callado. Nació siendo ya un hombre. Un hombre pequeño. La primera vez que yo me fijé en lo mucho que se parecían fue cuando lo vi a él ayudándole a devanar la lana enredada de un jersey viejo y a ovillarla para calcetar uno nuevo. Pinche con los brazos estirados hacia delante, firmes, en paralelo, sosteniendo la lana tensa. Los dos allí unidos por el hilo en movimiento. Ni una palabra. Devanando el silencio. (Rivas 2007: 213)

Lo que permite comprender mejor la situación de Pinche es el estado de Olinda durante el embarazo: traumatizada, está perdiendo ya, en este momento, su imagen positiva de sí misma -se encuentra en el primer estadio de su proceso de desconexión de la realidad. Un trauma prenatal o infantil no deja huellas profundas en la memoria sino que estas se plasman directamente en el cuerpo, en síntomas como por ejemplo una inquietud interior. Como expresión de esta inquietud interior, Pinche está caracterizado por sus dos caras como se puede comprobar en el siguiente fragmento:

Pero en la consulta me fui dando cuenta de que no sólo los ojos, sino las dos mitades de la cara eran muy diferentes. Por eso Pinche tenía cosas muy contradictorias. Podía ser el más valiente y el más cobarde. El más alegre y el más melancólico. El más bueno y el más malo. A lo mejor era todo por culpa del ojo. (Rivas 2007: 737-738)

Pinche comparte un fuerte sentimiento de solidaridad con la familia. Pero, en comparación con su hermana, se mantiene al margen. Su posición marginal está simbolizada por el papel que ocupa en relación al grupo familiar: ni es el portavoz de la madre, ni es el portador de los recuerdos o cómplice del padre en cuanto a la "batalla" contra el olvido.

\subsection{CONCLUSIÓN PARCIAL: SILENCIO Y DIÁLOGO ENTRE DOS GENERACIO- NES}

En relación a la familia Crecente, finalmente, hay que destacar dos cuestiones: Polca y Ó mantienen un diálogo directo sobre el pasado y contrastan con el silencio de Olinda y Pinche, los cuales somatizan el aspecto traumático del pasado. En consecuencia, se distinguen diferentes manifestaciones de un diálogo intergeneracional: una transmisión oral directa y una transmisión no verbal o, mejor dicho, psíquico-somática. 
La familia Crecente resulta ser una entidad colectiva parecida al sujeto individual: a través del diálogo se configura una memoria colectiva. Pero en este punto radica también la clave de la pregunta sobre la existencia de un traumatismo intergeneracional.

\section{MEMORIAS, OLVIDOS Y SILENCIO: TRANSMISIÓN INTERGENERACIONAL DEL TRAUMA}

Tal y como lo describe Kühner en su libro sobre trauma y memoria colectiva, un colectivo puede recordar y sufrir un mismo trauma (2008: 92). Olinda y Polca están marcados visible e invisiblemente. En el caso de Olinda eso significa que "todo aquello que estaba sucediendo producía un efecto sobre su cuerpo. Se veía fea. Había perdido el brillo de los ojos y del pelo. Depurada, impura. Casi no tenía leche para amamantar a la niña" (Rivas 2007: 206). Como se ha mencionado anteriormente, con el paso de tiempo, Olinda, incluso empieza a dudar sobre su identidad y su existencia:

Había mucha gente que no la veía. Y eso que estaba embarazada. Llegó a dudar de si existía o no. Había mucha gente desaparecida. Quizá ella misma también lo estaba sin saberlo. (...) Aquel incómodo injerto en su cuerpo era como llevar un reclamo, una garantía de realidad. O debería serlo. Pero lo que le preocupaba era que nadie, en su peregrinar burocrático para asegurarse el trabajo, hacía referencia a su estado. Nadie utilizó, ni siquiera escapada por rutina, la expresión «estado de buena esperanza», como si en su caso fuese una incorrección. Nadie la felicitaba. Una puede estar desaparecida, pensó Olinda, y estar embarazada. Ser real la criatura, pero tú no. (Rivas 2007: 204-205)

En lo que concierne a Polca, sus heridas traumáticas pueden ser visibles -"ha vuelto cojo. Cojo y todo (...)" (Rivas 2007: 325)- o interiores, en forma de pesadillas:

alguna vez había tenido la pesadilla de que le entraban insectos en el cuerpo. (...) El cuerpo era un lugar de conquista. (...) Y venían grupos con cosas aún más grandes. Con un grillo que insistían en meterle por la boca. Con fragmentos de la novela del hombre invisible. Su cuerpo iba a ser un depósito. (Rivas 2007: 762-763)
En ciertas situaciones, cuando las imágenes traumáticas vuelven con tanta fuerza, se queda sin aliento:

(...) se había olvidado de respirar. Se dio cuenta a tiempo. La piel ya le había cambiado de color. Y todo a su alrededor había cobrado una iluminación de arrebol, a punto de apagarse. La otra situación en que se olvidó de respirar fue cuando lo de las hormigas. Tenía mucha fiebre. Estaba convencido de estar bajo tierra. Las hormigas entraban por las heridas de las balas, pero también por todos los otros orificios del cuerpo. (...) Vaya, hombre. Hasta que se acordó de respirar. ¿Así que todo eso estaba escrito en el corazón? (Rivas 2007: 762-763)

Se comprueba así que estos dos personajes sufren una crisis enorme - un trauma primario. Esta crisis está provocada por un factor externo, la guerra, pero ocurre en la conciencia. $\mathrm{La}$ experiencia traumática desequilibra a los personajes, pero de forma diferente debido a sus personalidades, sus interpretaciones individuales del pasado y sus diferentes capacidades para la verbalización de los acontecimientos traumáticos. Resulta, por tanto, decisiva la diferenciación entre las preguntas: ¿por qué? o ¿para qué me ocurre esto? La guerra es una realidad, que no se puede cambiar, pero la conciencia sí, se puede cambiar. Sumamente interesante es el hecho de que independientemente de la generación, en la familia Crecente existen dos formas diferentes de reaccionar ante el trauma: el silencio y el olvido, representados por los personajes Olinda y Pinche y el recuerdo y el diálogo, representados por Polca y Ó, quienes debido a la integración de los recuerdos, por medio de verbalización y trabajo mental, pueden superar mejor su trauma sea un "trauma primario" o un "trauma secundario".

\section{CONCLUSIONES}

Para terminar y resumir los resultados del análisis se mencionarán algunas de las cuestiones centrales. En primer lugar, se destaca como los grupos sostenidos por estrechas relaciones de intimidad - por ejemplo, los núcleos familiares- son los verdaderos artífices de la configuración de una memoria del pasado contraria a la memoria oficial. Para garantizar 
este proceso la transmisión oral, sea directa o simbólica, es especialmente importante. Si la memoria dominante solo hace pública una versión de los hechos, las otras versiones deben transmitirse oralmente. Nuestro análisis destaca la importancia del diálogo intergeneracional para la identidad familiar, la transmisión de recuerdos y la garantía de la continuidad.

En segundo lugar, se comprueba cómo los recuerdos de la guerra no solo se transmiten a partir del diálogo, sino también a partir de los silencios ya que existen vivencias pasadas que no pueden ser integradas oralmente. En consecuencia, hay que distinguir entre diferentes dimensiones de un diálogo intergeneracional: la dimensión oral y la dimensión de lo no dicho, la dimensión del trauma y del silencio.

Por último, se observa cómo un colectivo puede recordar y sufrir un mismo trauma. Así se confirma un trauma primario para la generación directamente afectada y un trauma secundario para la generación sucesiva, que incorpora los aspectos traumáticos de los padres.
Con las diferentes perspectivas de los miembros familiares es posible hacerse una idea sobre las consecuencias psicosociales de la Guerra Civil y la dictadura, que se pudiera ampliar a la sociedad española: una parte es capaz de mantener vivo el diálogo, integrar los recuerdos y usar la memoria, otra parte no dispone de esta capacidad y deja caer los hechos históricos vividos en el olvido. Los miembros de esta familia, tanto si pertenecen a la primera generación o a la segunda, se mueven entre dos polos: el diálogo y la rememoración o el silencio y el olvido.

En Os libros arden mal, Manuel Rivas se apropia de la realidad fáctica para crear un mundo imaginado verosímil y avanzar en la recuperación de las memorias históricas. Rivas se sitúa del lado de los que recuerdan, igual que algunos de los miembros de la familia Crecente, e intenta, a través de la literatura -"un ser rumiante, donde fermenta lo interno y lo externo, lo vivido y lo imaginado, la razón y la emoción" (Rivas 2008: 215)- desdibujar la línea entre realidad y ficción con el fin de sacar del olvido partes de la historia de España.

\title{
5. REFERENCIAS BIBLIOGRÁFICAS
}

\author{
BIBLIOGRAFÍA PRIMARIA
}

Rivas, Manuel (2006): Os libros arden mal. Vigo: Xerais. (2007): Los libros arden mal (trad. Dolores Vilavedra). Madrid: Punto de Lectura. (2008): A cuerpo abierto. Madrid: Santillana.

\section{BIBLIOGRAFÍA SECUNDARIA}

Albert, Mechthild (2006): "Oralidad y memoria en la novela memorialística", en U. Winter (coord.), Lugares de memoria de la Guerra Civil y el franquismo: representaciones literarias y visuales. Madrid / Frankfurt am Main: Iberoamericana / Vervuert, pp. 21-38.

Assmann, Jan (2007): Das kulturelle Gedächtnis. München: Beck.

HalbWachs, Maurice (1952 [1925]): Les cadres sociaux de la mémoire. Paris: Les Presses universitaires de France.

KüHnER, Angela (2008): Trauma und kollektives Gedächtnis. Gießen: Psychosozial-Verlag.

Luengo, Ana (2004): La encrucijada de la memoria. La memoria colectiva de la Guerra Civil Española en la novela contemporánea. Berlin: Edition Tranvía. 